\author{
Richard H. GUY ${ }^{1}$ \\ Hidekazu KUMA ${ }^{2}$ \\ Masaru NAKANISHI ${ }^{2}$
}

${ }^{1}$ University of Bath,

Department of Pharmacy \& Pharmacology,

Claverton Down,

Bath, BA2 7AY, U.K

${ }^{2}$ Hisamitsu Pharmaceutical Co., Inc.,

R\&D Division

Kannondai 1-25-11, Tsukuba,

Ibaraki, Japan

Reprints: R. H. Guy

$<$ r.h.guy@bath.ac.uk>

Article accepted on 2/02/2014

\section{Serious photocontact dermatitis induced by topical ketoprofen depends on the formulation}

\begin{abstract}
Background: Topical administration of ketoprofen to treat local subcutaneous pain significantly reduces gastrointestinal and cardiovascular adverse effects associated with oral delivery. However, this benefit must be weighed against the risk of photosensitisation/phototoxicity. Objective: To substantiate the safety and efficacy of topical ketoprofen delivery from a patch. Methods: Experiments were performed, and published information analysed, (a) to confirm the superior skin permeability and pharmacological activity of ketoprofen, and (b) to demonstrate the lower incidence of ketoprofen photosensitisation/phototoxicity when delivered from a topical patch. Results: Ketoprofen's photodegradation products were more photoallergic than the drug itself. The period postketoprofen treatment that skin should be protected from UV radiation (while the drug is cleared from the application site) was estimated. Conclusions: Photosensitisation to ketoprofen can be mitigated by a patch formulation, which protects the drug from direct UV exposure during skin application, and reduces the formation of even more photoallergic photodegradation products.
\end{abstract}

Key words: ketoprofen, topical patch, skin, photocontact dermatitis
$\mathrm{T}$ he application of drugs to the skin is typically associated with two therapeutic objectives: (a) to deliver the active into the skin to treat dermatologic disease (often referred to as "topical" delivery), or (b) to deliver the compound through the skin and into the systemic circulation to achieve a central effect (so-called "transdermal" drug delivery) $[1,2]$. The former usually involves classic, topical formulations, such as creams, gels and ointments, while the latter is accomplished most commonly with an adhesive patch that may be able to sustain drug delivery over a period of up to one week.

Increasingly, though, drug administration to the skin is being used to relieve the pain associated with local, subcutaneous inflammation in joints and muscles, a goal which is distinct from those of topical and transdermal delivery [3]. In Asia, there is an established and very large market for a variety of products, particularly flexible, medicated patches, which deliver several non-steroidal antiinflammatory drugs (NSAIDs) for this purpose. Elsewhere, despite a much smaller (but now growing) commercial interest, there are nevertheless many gel formulations available both on prescription and over-the-counter.

The rationale underpinning these products is that NSAID delivery from the "outside-in", through the skin and into the subcutaneous compartment, is at least as efficient from a therapeutic standpoint as "inside-out" oral therapy $[4,5]$. Importantly, and in addition, the former, percutaneous approach results in significantly lower systemic exposure of the patient to the NSAID and essentially eliminates the majority of drug-related adverse effects, such as gastrointestinal disturbances and cardiovascular disorders (table 1) [6].
Nonetheless, there are other safety issues, which arise with topical NSAID delivery. In the case of ketoprofen, the specific drug of interest in this work, it is well-known that its topical application can cause photocontact dermatitis (PCD) [7-10], and that this has limited its use in certain parts of the world [11]. Recent statistics on the frequency of PCD [12-14] based on spontaneous adverse drug reaction reports, indicate that the use of a topical patch product results in an apparently smaller incidence of photoallergy relative to that observed when the drug is delivered from a conventional topical gel (table 2). While the under-reporting of ketoprofen-induced PCD has been highlighted, and remains a concern [9], it seems nonetheless reasonable to anticipate that the woven cloth backing of the topical patch blocks, at least in part, the interaction of UV radiation with the drug and the creation of potentially more sensitising photo-degradation products. The objective of this paper is to explore this thesis in more detail and to provide supporting evidence for the potential benefits of delivering ketoprofen from a topical patch.

\section{Methods}

\section{Pharmacokinetics of ketoprofen (KP) in vivo in man following oral dosing and topical delivery from either a patch or a gel}

Healthy male volunteers were dosed with ketoprofen via: (a) oral administration of either a standard tablet containing $100 \mathrm{mg}$ (Orudis [15], $\mathrm{n=7}$ ) or a sustained release (SR) 
Table 1. Serious adverse gastrointestinal (GI) and cardiovascular (CV) drug reactions to NSAIDs ${ }^{\mathrm{a}}$ in Europe from 2006 to 2012 following systemic and topical administration [6].

\begin{tabular}{|lcccc|}
\hline \multirow{2}{*}{$\begin{array}{l}\text { Adverse drug } \\
\text { reaction (ADR) }\end{array}$} & \multicolumn{2}{c|}{ Systemic administration } & \multicolumn{2}{c|}{ Topical administration } \\
\cline { 2 - 5 } & GI disorders & CV disorders & GI disorders & CV disorders \\
\hline Death & 86 & 24 & 1 & 0 \\
\hline Life-threatening & 386 & 60 & 15 & 2 \\
\hline Hospitalisation & 1,703 & 141 & 29 & 4 \\
\hline Sequelae & 13 & 3 & 1 & 0 \\
\hline Other serious ADR & 376 & 63 & 16 & 6 \\
\hline
\end{tabular}

${ }^{a}$ Specifically, ketoprofen, diclofenac, indomethacin, ibuprofen, niflumic acid and piroxicam.

Table 2. Incidence of ketoprofen-induced photocontact dermatitis according to spontaneous adverse drug reaction reports [12-14]. The frequencies represent the ratio of spontaneous photosensitivity events to the estimated number of patients treated.

\begin{tabular}{|c|c|c|c|c|c|}
\hline \multirow{2}{*}{ Formulation } & \multirow{2}{*}{$\begin{array}{l}\text { Estimated total } \\
\text { number of treated } \\
\text { patients (millions) }\end{array}$} & \multicolumn{2}{|c|}{$\begin{array}{l}\text { Photocontact } \\
\text { dermatitis }\end{array}$} & \multicolumn{2}{|c|}{$\begin{array}{l}\text { Frequency (per } \\
\text { million patients) }\end{array}$} \\
\hline & & Serious & Total & Serious & Total \\
\hline $\begin{array}{l}\text { Gel product in EU member } \\
\text { states (2001-08) }\end{array}$ & 36.2 & 111 & 169 & 3.07 & 4.67 \\
\hline $\begin{array}{l}\text { Patch product in EU member } \\
\text { states (2005-12) }\end{array}$ & 2.3 & 0 & 6 & N/A & 2.61 \\
\hline $\begin{array}{l}\text { Patch product in Japan } \\
(2001-2012)^{\mathrm{a}}\end{array}$ & 474.5 & 29 & 1,560 & 0.06 & 3.29 \\
\hline
\end{tabular}

${ }^{a}$ Use of ketoprofen gel in Japan is relatively uncommon, with only an estimated 0.5 million patients being treated between 2001 and $2012 ;$ in this time, only a single non-serious case of PCD has been reported. It should be noted that the marketed Japanese gel also contains a sunscreen.

formulation of $150 \mathrm{mg}$ (Orudis SR 150 [16], $\mathrm{n}=8$ ); (b) topical application over 24 hours of either a patch (Mohrus Tape, $20 \mathrm{mg}, 70 \mathrm{~cm}^{2}, \mathrm{n}=6$ ) or a gel (Sector gel [17], $300 \mathrm{mg}, 900 \mathrm{~cm}^{2}, \mathrm{n}=5$ ). Serum samples were obtained post-administration up to a maximum 72 hours at a frequency sufficient to obtain accurate estimates of $\mathrm{C}_{\max }$ and $\left.\mathrm{AUC}_{0 \rightarrow \infty}\right)$.

\section{Photodegradation products of KP in topical formulations}

A KP-containing patch (KEPLAT (Hisamitsu Pharmaceutical Co., Inc., Japan); $20 \mathrm{mg}$ of drug/70 $\mathrm{cm}^{2}$ was exposed to sunlight striking the backing surface. A KP gel (Profenid, Sanofi, France) was applied at a dose of $0.8 \mathrm{mg}$ of drug in $20 \mathrm{mg}$ of formulation over $70 \mathrm{~cm}^{2}$ of a polyethylene terephthalate film and was exposed to sunlight. Control experiments involved the same exposure conditions with the delivery systems completely covered by aluminum foil. The cumulative amount of ultraviolet light exposure (i.e., natural sunlight in Japan during January) over an 8-hour period was $15 \mathrm{~W} . \mathrm{hr} / \mathrm{m}^{2}\left(5.41 \mathrm{~J} / \mathrm{cm}^{2}\right)$. Post-exposure, the drug and any photodegradation products were extracted from the patch with tetrahydrofuran (shaking for 30 minutes with $50 \mathrm{~mL}$ of the solvent). $2 \mathrm{~mL}$ of this extract was diluted to $100 \mathrm{~mL}$ with methanol, and $15 \mu \mathrm{L}$ of this solution was analysed by HPLC (Shimadzu-XR, Shimadzu Corp., Kyoto, Japan) with UV detection $(254 \mathrm{~nm})$ using a silica-based reversed phase column (TSK-gel ODS-120T, Tosoh Corp., Tokyo, Japan), and a mobile phase comprising a 1:1 v/v mixture of $0.1 \%$ acetic acid and acetonitrile. The same procedure was adopted for extracting drug and any photodegradation products from the gel, except that the extraction solvent, in this case, was a $1: 1 \mathrm{v} / \mathrm{v}$ mixture of water and methanol.

\section{Photosensitisation potential of KP and its photodegradation products}

Photosensitisation and photochallenge of female guinea pigs (Hartley, Japan Laboratory Animals Inc. Tokyo, Japan; $\mathrm{n}=8$ for the irradiated group, $\mathrm{n}=10$ for the control, non-irradiated animals) were conducted using a modified version of the adjuvant and tape-strip method described previously [18]. On day $0,0.1 \mathrm{~mL}$ of an emulsified $1: 1$ v/v mixture of Freund's complete adjuvant (Wako Pure Chemical Industries, Ltd., Japan) and saline was injected subcutaneously at each of the 4 corners of an $8 \mathrm{~cm}^{2}$ area of the animal's neck (the hair at this region having been clipped carefully in advance). After stripping the stratum corneum with adhesive tape (CELLOTAPE, Nichiban Co., Ltd. Tokyo, Japan) approximately 20 times, $1 \mathrm{~mL}$ of an $8 \% \mathrm{w} / \mathrm{v}$ solution of KP, or of one of its photodegradation products (3-(1-hydroxy) ethyl benzophenone (KP-OH), 3acetyl benzophenone (Ac-KP) and 3-ethyl benzophenone (KP-Et)), was applied and irradiated with UVA at $10 \mathrm{~J} / \mathrm{cm}^{2}$. The time of exposure to the drug or its photodegradation 
products was 4 hours. The procedure was repeated once daily for 5 consecutive days. On day 21 post-initiation of the experiment, $20 \mu \mathrm{L}$ of $0.5 \%, 2 \%$ and $8 \% \mathrm{w} / \mathrm{v}$ solutions of $\mathrm{KP}, \mathrm{Et}-\mathrm{KP}, \mathrm{KP}-\mathrm{OH}$ and Ac-KP, were separately applied to $2.25 \mathrm{~cm}^{2}$ of dorsal skin (again, pre-clipped) and irradiated with $10 \mathrm{~J} / \mathrm{cm}^{2}$ UVA. The exposure time to the chemicals was 4 hours. Skin reactions at the photochallenged sites were graded at 24 and $48 \mathrm{~h}$ after UVA irradiation, using a Draize scale [19].

\section{Photoallergic responses in guinea pig and mouse following topical exposure to a ketoprofen patch and a ketoprofen gel}

In guinea pigs, exactly the same procedure as described above was followed except that (a) the sensitisation phase involved exposure to either $8 \mathrm{~cm}^{2}$ of a KP patch (KEPLAT, Hisamitsu Pharmaceutical Co., Inc., Japan)) or $90 \mathrm{mg}$ of a KP gel (Ketum, Menarini, Italy), and (b) the challenge phase involved exposure of the animal's back skin to either $4 \mathrm{~cm}^{2}$ of the patch or $45 \mathrm{mg}$ of the gel. The patch areas and quantities of gel applied ensured that equivalent amounts of ketoprofen were administered by the two dosage forms. To evaluate photosensitivity in mice, a modified local lymph node assay (LLNA) was employed [20]. Female mice (BALB/c, Japan SLC, Inc. Hamamatsu, Japan) were treated with either $1 \mathrm{~cm}^{2}$ of a KP patch (KEPLAT) or $11.4 \mathrm{mg} / \mathrm{cm}^{2}$ of a KP gel (Ketum) on both sides of each ear, and irradiated with $40 \mathrm{~J} / \mathrm{cm}^{2}$ of UVA $\left(3.1 \mathrm{~mW} / \mathrm{cm}^{2}, 3.5\right.$ hours $)$ during the application. After the irradiation, the KP formulations were removed (application time was 4 hours). Photosensitization was then performed on three consecutive days, with the mice being additionally irradiated with $40 \mathrm{~J} / \mathrm{cm}^{2}$ of UVA after formulation on the third day. On the fifth day after initiation of the experiment, the mice were injected intravenously with $250 \mu \mathrm{L}$ of phosphate-buffered saline at pH 7.4 (PBS) containing $20 \mu \mathrm{Ci}\left[\right.$ methyl- ${ }^{3} \mathrm{H}$ ] thymidine $\left({ }^{3}\right.$ HTdR, Moravek Biochemicals, USA). Mice were sacrificed 5 hours later, and the draining auricular lymph nodes were excised. Single cell suspensions of lymph node cells (LNC) were prepared by gentle mechanical disaggregation. LNC were centrifuged at 1,100 rpm for 10 minutes, washed twice with $3 \mathrm{~mL}$ of PBS and re-suspended with $3 \mathrm{~mL}$ of $5 \%$ $\mathrm{v} / \mathrm{v}$ trichloroacetic acid (TCA). After overnight incubation at $4{ }^{\circ} \mathrm{C}$, the precipitate was recovered by centrifugation, resuspended with $1 \mathrm{~mL}$ of $5 \%$ TCA and transferred into $10 \mathrm{~mL}$ of scintillation fluid. ${ }^{3} \mathrm{HTdR}$ incorporation was measured by scintillation counting (Hitachi Aloka Medical, Ltd., Tokyo, Japan). Statistical analysis was performed using a Tukey type multiple comparison and SAS software (SAS Institute Japan Ltd, Tokyo, Japan).

\section{Skin concentration of KP in human patients after topical application of a patch}

The ketoprofen patch (Mohrus Tape, Hisamitsu Pharmaceutical Co., Inc., Japan) was applied to 14 patients with osteoarthritis or other orthopaedic disease prior to arthrocentesis or a similar procedure. After removal of the patch, arthritic lesion tissues were obtained and stored in a freezer until analysis. The local skin concentration of ketoprofen was measured as follows. About $200 \mathrm{mg}$ of skin was minced and homogenized in methanol. The filtered liquid was evaporated, re-dissolved in acidic solution and extracted with ethyl ether. The organic phase was evaporated and the residue was methylated with ethereal diazomethane. Once the methylated KP had been separated using TLC, it was quantified by gas chromatography-mass spectrometry (gas chromatograph: HP 5890 Series II Gas Chromatograph (Hewlett Packard, Waldbronn, Germany); mass spectrometer: JMS SX102A (JEOL Ltd, Tokyo, Japan); column: J\&W DB-17 $(15 \mathrm{~m} \times 0.25 \mathrm{~mm}, 0.25 \mu \mathrm{m}$, Agilent Technologies, Inc, CA, USA)).

\section{Results and discussion}

\section{Establishing the efficacy of topical ketoprofen delivery}

Figure 1 illustrates the impact of administration route on two key pharmacokinetic parameters (maximum plasma concentration $\left(\mathrm{C}_{\max }\right)$ and area under the plasma concentration versus time profile $\left(\mathrm{AUC}_{0 \rightarrow \infty}\right)$ ) for ketoprofen in man. Notably, $\mathrm{C}_{\max }$ is $10-100$ times higher after systemic administration (oral $[15,16]$ ) compared to that achieved following topical application of a patch or a gel [17].

There are obviously many NSAIDs available for topical delivery to the subcutaneous compartment and the selection of an appropriate candidate must take into account both the potency of the drug and its ability to be absorbed to the site of action. It is self-evident, therefore, that even a compound with sub-nanomolar potency at the target receptor is never going to be a useful drug unless it is capable of penetrating the skin.

Information in the literature enables this evaluation to be performed with relative ease and the data available on

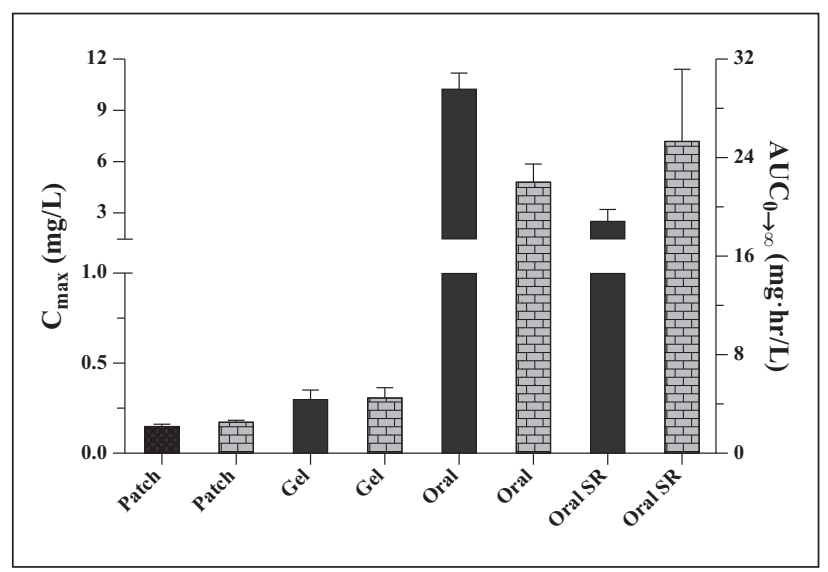

Figure 1. Ketoprofen pharmacokinetics $\left(\mathrm{C}_{\max }\right.$ solid bars; $\mathrm{AUC}$ stippled bars) in man after (A) topical application of either a patch (Mohrus Tape, $20 \mathrm{mg}, 70 \mathrm{~cm}^{2}, \mathrm{n}=6$ ) or a gel (Sector gel [17], $300 \mathrm{mg}, 900 \mathrm{~cm}^{2}, \mathrm{n}=5$ ), and (B) oral administration of either a standard tablet containing $100 \mathrm{mg}$ (Orudis [15], $\mathrm{n}=7$ ) or a sustained release (SR) formulation of $150 \mathrm{mg}$ (Orudis $\mathrm{SR} 150$ [16], $\mathrm{n}=8$ ). The $\mathrm{C}_{\max }$ and AUC (mean \pm SD) postapplication of the patch were $0.14( \pm 0.02) \mathrm{mg} / \mathrm{L}$ and 2.45 $( \pm 0.20) \mathrm{mg} * \mathrm{hr} / \mathrm{L}$, respectively. 

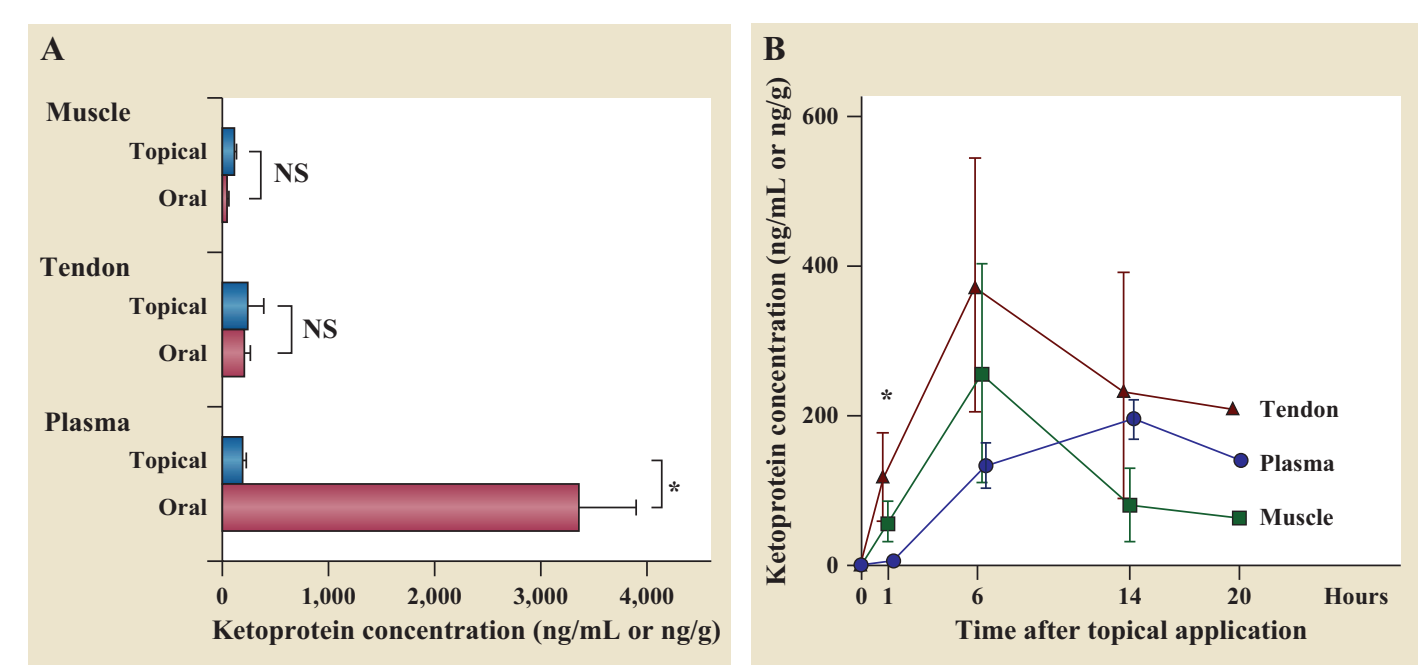

Figure 2. A) Ketoprofen levels (mean $\pm S E ; n=6$ ) 14 hours post-patch and oral administration in muscle, tendon and plasma. B) Temporal evolution of ketoprofen concentrations (mean $\pm \mathrm{SE}$ ) in muscle, tendon and plasma after drug delivery from a topical patch. Significant differences $(\mathrm{P}<0.05)$ are indicated by asterisks [24].

NSAID skin permeability in man [21], COX inhibition in vitro [22], and anti-inflammatory activity in vivo in rats [23], identify ketoprofen as a clear 'lead' for topical delivery to achieve an anti-inflammatory effect. Furthermore, a pivotal pharmacokinetic study in patients scheduled for knee surgery has demonstrated that a topical patch formulation (Mohrus Tape) is able to achieve equivalent concentrations in subcutaneous tissue compartments, such as muscle and tendon, as those measured after oral administration of the drug [24] (Figure 2A); however, as previously discussed, the systemic exposure to ketoprofen (as measured by the plasma concentration) when delivered transdermally is significantly smaller, by more than two orders of magnitude, relative to that following oral dosing. In addition, the temporal evolution of ketoprofen concentrations in muscle and tendon are similar, yet noticeably different from that in plasma, providing additional evidence that the drug is reaching these subcutaneous targets from "outside-in", and not via redistribution from the central compartment (Figure 2B) [24].

\section{Safety issues associated with topical ketoprofen delivery}

Table 3 shows the effect of UVA irradiation $\left(5.41 \mathrm{~J} / \mathrm{cm}^{2}\right)$ on ketoprofen in topical gel (Ketum) and patch (KEPLAT) products. The woven cloth backing of the topical patch clearly prevented the UVA light from interacting with the drug to form some of its principal photodegradation products, 3-(1-hydroxy) ethyl benzophenone (KP-OH), 3-acetyl benzophenone (Ac-KP) and 3-ethyl benzophenone (KP$\mathrm{Et}$ ), the structures of which are shown in the table 3. In contrast, the drug in the gel was significantly degraded, such that less than $20 \%$ of the original quantity was ultimately recoverable.

To confirm the relevance of the above findings, a photosensitisation assay [18] was performed in guinea pigs comparing ketoprofen with the three photodegradation products identified in table 3 . The results were expressed in terms of an overall score, which reflected the sum of two skin reactions (i.e., erythema and edema) using Draize test

Table 3. Formation of the most common ketoprofen photodegradation products when a topical gel and a topical patch are exposed to UVA irradiation.

\begin{tabular}{|c|c|c|c|c|c|}
\hline \multirow{3}{*}{ Dosage form } & \multirow{3}{*}{ UVA exposure } & \multirow{2}{*}{ Ketoprofen } & \multicolumn{3}{|c|}{ Ketoprofen photodegradation products (\%) } \\
\hline & & & KP-OH & Ac-KP & KP-Et \\
\hline & & & & & \\
\hline \multirow[b]{2}{*}{ Patch } & $(-)$ & 100.0 & - & - & - \\
\hline & $(+)$ & 97.0 & - & 0.1 & - \\
\hline \multirow{2}{*}{ Gel } & $(-)$ & 100.0 & - & - & - \\
\hline & $(+)$ & 18.2 & 4.2 & 15.9 & 10.5 \\
\hline
\end{tabular}


Table 4. Photosensitisation potential of ketoprofen and its photodegradation products. The scores in the right-hand columns reflect the sum of skin erythema and edema skin reactions assessed using Draize test criteria.

\begin{tabular}{|c|c|c|c|c|c|c|}
\hline \multirow{3}{*}{$\begin{array}{l}\text { Test } \\
\text { Chemical }\end{array}$} & \multicolumn{2}{|c|}{ Chemical Conc. $(\%$ w/v $)$} & \multicolumn{4}{|c|}{ Score $($ Mean \pm S.D.) } \\
\hline & \multirow{2}{*}{ Induction } & \multirow{2}{*}{ Challenge } & \multicolumn{2}{|c|}{$\begin{array}{l}\text { Induction/UVA(-) } \\
\text { Challenge/UVA(+) }\end{array}$} & \multicolumn{2}{|c|}{$\begin{array}{l}\text { Induction/UVA(+) } \\
\text { Challenge/UVA(+) }\end{array}$} \\
\hline & & & $24 \mathrm{~h}$ & $48 \mathrm{~h}$ & $24 \mathrm{~h}$ & $48 \mathrm{~h}$ \\
\hline \multirow{3}{*}{$\mathrm{KP}$} & \multirow{3}{*}{8} & 0.5 & \multirow{3}{*}{0.0} & \multirow{3}{*}{0.0} & $1.1 \pm 0.8$ & $1.8 \pm 1.0$ \\
\hline & & 2.0 & & & $1.9 \pm 1.0$ & $2.9 \pm 1.4$ \\
\hline & & 8.0 & & & $2.4 \pm 0.7$ & $3.5 \pm 1.1$ \\
\hline \multirow{3}{*}{$\mathrm{KP}-\mathrm{OH}$} & \multirow{3}{*}{8} & 0.5 & \multirow{3}{*}{0.0} & \multirow{3}{*}{0.0} & $3.3 \pm 1.4$ & $4.1 \pm 1.1$ \\
\hline & & 2.0 & & & $3.4 \pm 1.2$ & $4.4 \pm 0.9$ \\
\hline & & 8.0 & & & $3.3 \pm 1.0$ & $4.5 \pm 0.8$ \\
\hline \multirow{3}{*}{ Ac-KP } & \multirow{3}{*}{8} & 0.5 & \multirow{3}{*}{0.0} & $0.1 \pm 0.4$ & $1.8 \pm 1.4$ & $1.8 \pm 1.4$ \\
\hline & & 2.0 & & $0.4 \pm 0.5$ & $2.3 \pm 1.2$ & $3.1 \pm 1.6$ \\
\hline & & 8.0 & & $1.0 \pm 0.9$ & $2.5 \pm 1.3$ & $3.4 \pm 1.4$ \\
\hline \multirow{3}{*}{ Et-KP } & \multirow{3}{*}{8} & 0.5 & \multirow{3}{*}{0.0} & \multirow{3}{*}{0.0} & $3.3 \pm 0.9$ & $3.8 \pm 1.3$ \\
\hline & & 2.0 & & & $3.8 \pm 0.5$ & $4.5 \pm 0.5$ \\
\hline & & 8.0 & & & $4.5 \pm 0.5$ & $5.0 \pm 0.0$ \\
\hline
\end{tabular}

Table 5. Sensitisation scores, at 24 and 48 hours postchallenge, determined (in the same way as those summarised in table 4) in a photosensitisation test in guinea pigs treated with either a topical ketoprofen gel (Ketum) or a topical patch (KEPLAT).

\begin{tabular}{|lcc|}
\hline \multirow{2}{*}{ Formulation } & \multicolumn{2}{c|}{ Score (Mean \pm S.D.) } \\
\cline { 2 - 3 } & $\mathbf{2 4} \mathbf{~ h}$ & $\mathbf{4 8 ~} \mathbf{~ h}$ \\
\hline KP Gel $(\mathrm{n}=6)$ & $3.3 \pm 1.2$ & $3.5 \pm 0.8$ \\
\hline KP Patch $(\mathrm{n}=6)$ & $0.5 \pm 0.8$ & $0.8 \pm 1.2$ \\
\hline
\end{tabular}

criteria [19], and are summarised in table 4. The data reflect a dose-dependent response to ketoprofen, Ac-KP and Et-KP (but less obviously to KP-OH for as yet unknown reason); in addition, it is clear that $\mathrm{KP}-\mathrm{OH}$ and Et-KP are stronger photoallergens, suggesting (in line with the information in table 3) that the risk of photosensitisation from a topical ketoprofen gel is greater than that from a topical patch. At present, there is no reason to suspect that the ketoprofen photoproducts have any potential to induce a $\mathrm{T}$-cell response in the absence of UVA radiation.

A further photosensitisation test was performed in guinea pigs that had been treated with either a topical ketoprofen gel (Ketum) or a topical patch (KEPLAT) containing the drug (table 5). At 24 and 48 hours post-challenge, the average sensitisation scores (determined in the same way as the experiments summarised in table 4) at the gel-treated sites were significantly higher than those at the sites to which the topical patch had been applied, confirming the conclusions deduced before.

Finally, a photo local lymph node assay (photo LLNA, a modified form of the well-known LLNA [20]) was performed in mice. In this experiment, the extent of photosensitisation is determined by the uptake of ${ }^{3} \mathrm{H}$-thymidine and the results are presented in Figure 3. The photoallergic response after treatment with ketoprofen gel was

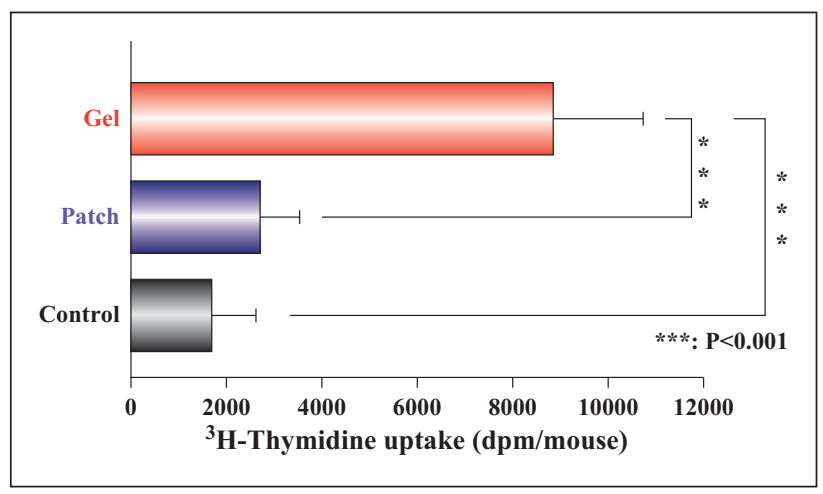

Figure 3. Photoallergic responses following a modified photoLLNA in mice treated with either a ketoprofen gel or a topical patch containing the drug. Incorporations of ${ }^{3} \mathrm{H}$-thymidine (Mean $( \pm \mathrm{SD}) ; \mathrm{n}=7)$ at the control, patch and gel-treated sites were $1736( \pm 903), 2722( \pm 815), 8827( \pm 1951) \mathrm{dpm} / \mathrm{mouse}$, respectively.

significantly greater $(\mathrm{P}<0.001)$ than that either (i) following treatment with the patch, or (ii) subsequent to the no-treatment control. In contrast, patch and control results were not significantly different.

\section{Mitigating the risk of residual ketoprofen in skin post-treatment}

The analysis of the collective data presented above fully supports the selection of ketoprofen as a suitable NSAID candidate to treat subcutaneous inflammation, and that a topical patch formulation of the drug has significant advantages over a conventional gel with respect to the likely incidence of photocontact dermatitis. However, while the woven cloth backing of the patch clearly blocks skin irradiation while in place on the skin, it has no such effect once removed. Consequently, because dermal drug clearance is 
Table 6. Ketoprofen concentrations in plasma and skin after oral administration of a $50 \mathrm{mg}$ immediate release tablet in man [27].

\begin{tabular}{|lll|}
\hline $\begin{array}{l}\text { Time after oral } \\
\text { dosing (hours) }\end{array}$ & $\begin{array}{l}{[\text { Ketoprofen }]_{\text {plasma }}} \\
(\mu \mathbf{g} / \mathbf{m L})\end{array}$ & $\begin{array}{l}{[\text { Ketoprofen }]_{\text {skin }}} \\
(\mu \mathbf{g} / \mathbf{g})\end{array}$ \\
\hline 2 & 2.25 & 2.06 \\
\hline 6 & 0.24 & 0.34 \\
\hline 14 & 0.03 & $<\mathrm{LOQ}^{\mathrm{a}}$ \\
\hline
\end{tabular}

${ }^{a}$ Below the limit of quantitation $(L O Q)$.

principally controlled by slow percutaneous diffusion [25], there remains an important risk that, upon patch removal, PCD will be initiated due to UV light falling on skin in which there is residual drug in the epidermis/dermis that is still being absorbed.

A logical approach to this issue is to ensure that the skin, post-removal of the patch, is protected from UV-exposure for a period sufficient to ensure that ketoprofen levels in the cutaneous tissue have fallen to a level which is insufficient to trigger PCD. How can this be determined?

It is known that the risk of PCD when ketoprofen is taken orally is extremely low [26]. It follows that if the drug levels in skin after patch removal have decreased to below those observed when the drug is taken orally, then it should be safe to terminate protection of the treated site. Table 6 presents the plasma and skin concentrations of ketoprofen in man as a function of time after oral administration of a $50 \mathrm{mg}$ immediate release tablet [27]. The maximum concentration attained in the skin was approximately $2 \mu \mathrm{g} / \mathrm{g}$. As this level poses minimal concern in terms of provoking PCD, it follows that this is the concentration to which residual ketoprofen in skin beneath the patch-treated site must decrease before UV exposure can be allowed to occur. Measurements in human patients after using a ketoprofen patch showed that the average steady-state skin concentration of the drug was $109( \pm 157) \mu \mathrm{g} / \mathrm{g}$, with the maximum value observed being $521 \mu \mathrm{g} / \mathrm{g}$. Assuming that the skin clearance half-life from human skin is similar to that which has been measured in guinea pigs (i.e., about 1.5 days [28]), and that first-order kinetics are operative, it is straightforward to calculate that it would require $\sim 12$ days for this maximal level of ketoprofen in skin to decrease to $2 \mu \mathrm{g} / \mathrm{g}$. Conservatively, therefore, a 2-week period of photoprotection post-removal of a ketoprofen patch should minimise or eliminate any risk of drug-associated $\mathrm{PCD}^{1}$.

\section{Conclusions}

The rationale for treating local subcutaneous inflammation with topical NSAIDs is logical and supported by experimental and clinical data; in addition, there is clear evidence for reduced adverse effects when using this approach (as compared with oral delivery). The pharmacological activity and skin permeability of ketoprofen makes this drug an

\footnotetext{
${ }^{1}$ Of course, should it be shown that any of the ketoprofen photodegradation products have slower skin clearance than the drug itself, this period would need to be prolonged.
}

excellent choice for delivery via the skin. Importantly, the known risk of ketoprofen-induced photocontact dermatitis is significantly less when using a topical ketoprofen patch than that for a gel product, most probably due to the protective role of the woven cloth backing. Nonetheless, even when a patch is used, it is essential to protect the skin from UV exposure post-application to prevent photocontact dermatitis, most sensibly for a period of about 2 weeks.

Disclosure. Financial support: This research was funded by Hisamitsu Pharmaceutical Co., Inc. Conflict of interest: none.

\section{References}

1. Guy RH. Transdermal drug delivery. Handb Exp Pharmacol 2010; 197: 399-410.

2. Kalia YN, Merino V, Guy RH. Transdermal drug delivery. Clinical aspects. Dermatol Clin 1998; 16: 289-99.

3. Weiss SC. Conventional topical delivery systems. Dermatol Ther 2011; 24: 471-6.

4. Barkin RL. Topical Nonsteroidal Anti-Inflammatory Drugs: The importance of Drug, Delivery, and therapeutic outcome. Am J Ther 2012; Feb 22 [Epub ahead of print].

5. Mazières B. Topical ketoprofen patch. Drugs R D 2005; 6: 337-44.

6. Vigibase: Uppsala Monitoring Centre (UMC) database. Information downloaded on May 27, 2013.

7. Tokura Y. Photoallergy. Expert Rev Dermatol 2009; 4: 263-70.

8. Cusano $F$, Rafenelli $A$, Bacchilega $R$, et al. Photo-contact dermatitis from ketoprofen. Contact Dermatitis 1987; 17: 108-9.

9. Kerr AC. A European multicentre photopach test study. Br J Dermatol 2012; 166: 1002-9.

10. Sugiura $M$, Hayakawa $R$, Kato $Y$, et al. 4 cases of photocontact dermatitis due to ketoprofen. Contact Dermatitis 2000; 43: 16-9.

11. Ketoprofen gels: unfortunately back on the French market. Prescrire Int 2010; 109: 204-5.

12. Rapporteur (France) EMEA/H/A-107/1259 assessment report Ketoprofen-containing medicinal products for topical use (Safety Data) for Committee for Human Medicinal Products (CHMP) 13/01/2010.

13. Co-rapporteur's assessment report EMEA/H/A-107/1259 Ketoprofen containing medicinal products for topical use 4/05/2010.

14. Rapporteur (France) EMEA/H/A-107/1259 assessment report Ketoprofen-containing medicinal products for topical use (Third List of Questions) for Committee for Human Medicinal Products (CHMP) 13/01/2010.

15. Sasaki T, Ishizaki T, Suganuma T, et al. Pharmacokinetics of ketoprofen following single oral, intramuscular, rectal and repeated oral administration. The Ryumachi 1984; 21:277-89.

16. Koike Y, Ebihara A, Ohashi K. Phase I study of RPY-001, a controlled release capsule of ketoprofen. Clin Pharmacol Ther 1989; 17: 287-309.

17. Sasai $Y$, Nagata M, Ogawa A, et al. Absorption, metabolism and systemic effects after cutanious application of KPG-200 in healthy volunteers. Jpn Pharmacol Ther 1984; 12: 2273-84.

18. Ichikawa $H$, Armstrong RB, Harber LC. Photoallergic contact dermatitis in guinea pigs:_Improved induction technique using Freund's complete adjuvant. J Invest Dermatol 1981;76: 498-501.

19. Draize JH, Woodard G, Calvery HO. Methods for the study of irritation and toxicity of substances applied topically to the skin and mucous membranes. J Pharmacol Exp Ther 1944; 377-90.

20. Kimber I, Dearman R, Basketter DA, et al. The local lymph node assay: past, present and future. Contact Dermatitis 2002; 47: 315-28. 
21. Yano $Y$, Nakagawa $A$, Tsuji $M$, et al. Skin permeability of various Non-steroidal Anti-inflammatory Drugs in man. Life Sciences 1986; 39: 1043-50.

22. Tanida $N$, Maekawa $K$, Nakanishi $M$. Topical applications for pain and arthritic diseases. Arthritis 2011 ; 12: 165-82.

23. Komatsu T, Sakurada T. Comparison of the efficacy and skin permeability of topical NSAID preparations used in Europe. Eur J pharm sci 2012; 47: 890-5.

24. Sekiya I, Morito T, Hara K, et al. Ketoprofen absorption by muscle and tendon after topical or oral administration in patients undergoing anterior cruciate ligament reconstruction. AAPS PharmSciTech 2010; $11: 154-8$.
25. Scheuplein RJ. Mechanism of percutaneous absorption II. Transient diffusion and the relative importance of various routes of skin penetration. J Invest Dermatol 1967; 48: 79-88.

26. Foti $C$, Cassano N, Vena GA, et al. Photodermatitis caused by oral ketoprofen: two case reports. Contact Dermatitis 2011; 64:181-3.

27. Christer $R$, Tomas $M, B$ jorn $E$, et al. An open, randomized study of ketoprofen in patients in surgery for achilles or patellar tendinopathy. J Rheumatol 1997; 24: 1595-8.

28. Yano $T$, Wada $M$, Furukawa $K$, et al. Absorption, distribution and excretion of ketoprofen after topical application of a $\left[{ }^{14} \mathrm{C}\right]$ ketoprofen-containing tape preparation to guinea pigs. lyakuhin Kenkyu 1993; 24:727-41. 